\title{
On Shared Indefinite Expressions in Coordinative Structures*
}

\begin{abstract}
The paper shows that shared indefinite expressions in coordinative constructions may differ with respect to their referential properties. This is due to their being cither in a focused or in a nonfocused shared constituent. Their different information-structural status follows from Rooth's theory on focus interpretation. Thus it follows that focused shared constitutents must be beyond the actual coordination and that coordinative constructions with unfocused shared constituents can be represented as ellipsis. In a focused shared constituent indefinite expressions may have a specific and an non specific unique reading as well as an non specific distributive one. For the latter we outline the idea that subjects and objects in the actual coordination form a pair of sets to which a distributing operator is attached. The set formation is further supported by plural pronouns referring to the respective set and by plural verb agreement in subsequent expressions.
\end{abstract}

\section{Introduction}

The paper will focus on the syntax and semantics of indefinites which are contained in constituents shared by the conjuncts of a coordinate construction. Pretheoretically, 'shared constituents' are to be understood as constituents that are somehow present in all conjuncts. It depends on the respective syntactic theory whether such shared constituents are considered to be within the actual coordination or beyond it. In the ellipsis approach, the 'shared constituent' consists of an overt expression and a deleted or not phonologically expressed pendant (Wilder 1994, 1995). The overtly expressed constituent may either be in the initial conjunct or in the final one. The Across-The-Board-Theory (ATB) or the Ride-Node-Raising Theory (RNR), on the other hand, consider shared constituents to be extracted out of the actual coordination (Williams (1978)). To give an impression of what is meant by ellipsis and extraposition in coordination, examples (1) and (2) illustrate ellipsis and examples (3) and (4) ATB and RNR, respectively.

(1) [ HANS hat MARIA und [PAUL hat ANNA scinen alten Lehrer vorgestellt] Hans has Maria, Dat. 'Hans introduced to Maria, and Paul to Anna, his old teacher.'

(2) [Einen Gast $t_{i}$ [hat SIE jedem MÄDCHEN $e_{i}$ ]] und [erat ER jedem JUNGEN $e_{i}$ vorgestellt]] a guest has she to every girl and a guest has he to every boy introduced 'It was a guest that she introduced to every girl and he to cvery boy.'

(3) [Hans begrüßt $e_{i}$ und Paul küß $e_{i}$ ] [seinen ehemaligen LEHRER $]_{i}$ Hans welcomes and Paul kisses his former teacher. 'Hans welcomes and Paul kisses his old tcacher.'

\footnotetext{
* This article will be published as a extended version together with Klaus von Heusinger in the Journal of Semantics this year.
} 
(4) [Einen LeHRER $]_{i}\left[\right.$ hat jeder Schüler $e_{i}$ gelobt und hat jede Schülerin $e_{i}$ kritisiert. A teacher, Acc has every schoolboy, Nom. praised and has every schoolgirl criticized 'It was a teacher that every schoolboy praised and every schoolgirl criticized.'

One of the claims of the paper will be that the syntactic representation of such constructions as ellipsis or ATB or RNR, respectively, depends on the information structural status of the shared constituent. The same holds for the unique or distributive reading of indefinites being in shared constituents.

As is commonly known, indefinites found in the connex of a quantifier like every may have either a distributive or a unique reading. Similarly, indefinites which are involved as shared constituents in coordination can be interpreted in this twofold way. But if we take a look at the following examples, we will observe that these two readings are restricted by the focusing or non-focusing of the shared constituents.

Our observations will be guided by two parameters: the focusing or defocusing of the indefinite and its specific or non specific reading. As will be seen in section 3.2 we mean by the 'specific reading' of an indefinite that it denotes an entity that is becomes anchored in the discourse context and by the 'non specific reading' that the entity remains un-anchored. To begin, if the indefinite is in focus, it may have a specific, unique reading. This means it denotes only one entity which is contextually anchored. ${ }^{1}$

(5) A: Was machten Hans und Anna und Paul und Frieda in der Galerie?

What did Hans and Anna and Paul and Frieda in the picture gallery?

B: Hans hat Anna und Paul hat Frieda [F ein BlLD gezeigt]

Hans has Anna, Dat. and Paul has Frieda, Dat. a picture shown

'Hans showed Anna, and Paul Frieda, a picture.'

That the referent of the indefinite is a specific one becomes obvious when the referent receives additional specification. Thus the referent denoted by ein Bild can be specified further by the predication be by Picasso in a subsequent utterance of B such as It was by Picasso. This further specification indicates that there is somebody (here the speaker) who, being capable of further specifiying the denotee, may identify it with an individual. The specificity of the referent can be proven in that it can be referred to by a singular pronoun. It seems nearly trivial to state such constructions refer to two specific pictures. If $\mathrm{B}$ wanted to refer to two specific pictures he should modify the indefinite expression by a specificity-indicating adjective such as gewisser or bestimmter (certain) and he should add an overtly expressed distributing operator like jeweils (each) to mark distributivity - cf. (6).

(6) Hans hat Anna und Paul hat Frieda jeweils ${ }_{F}$ ein bestimmtes BILD gezeigt] Hans has Anna, Dat. and Paul has Frieda, Dat. each a certain picture shown. 'Hans showed Anna, and Paul Frieda, cach a certain picture. '

Another way to refer to two specific pictures is to give up the shared constituent and instead use two specificity indicating indefinite expressions. But then it is necessary to insert the focused adverbial auch (too) to prevent information-structural asymmetry, and one may omit the deaccented material in the second conjunct $-\mathrm{cf} .(7)$.

\footnotetext{
1 Constituents carrying the 'main' focus accent are written in capitals.
} 
(7) Hans hat Anna [F ein bestimmtes BILD gezeigt] und Hans has Anna a certain picture shown and

Peter hat Frieda [F AUCH ein bestimtes Bild gezeigt]

Peter has Frieda too a certain picture shown

'Hans showed a certain picture to Anna as did Peter to Frieda.'

In addition to the specific reading, the focused shared constituent in (5)B can get an non specific one. With this non specific reading it may get a unique as well as a distributive interpretation. Having the unique reading, it refers to a single referent, and when interpreted distributively, it refers to two referents. The two referents as well as the single one cannot be referred to by a pronoun like it or them in a subsequent sentence such as Anna and Frieda liked it/them. Instead, the referents can only be referred to by a definite expression like the picture or the pictures, respectively.

But notice that a singular pronoun in a subsequent sentence may be coreferent with a distributively interpreted indefinite if it is in the connex with a plural set.

(8) Erst kaufte Hans Maria und Paul Anna [Fein AuTO] und dann haben Maria und First bought Hans Maria, Dat. and Paul Anna, Dat. a car and then have Maria and

Anna es angemeldet.

Anna it registered

'First, Hans bought Maria, and Paul Anna, a car and then Maria and Anna registered it.'

Beyond the specific unique reading where one car is bought, the clause First, Hans bought Maria, and Paul Anna, a car. can have a distributive one, where both Maria and Anna received a car. What we may assume here is that the set denoted by the conjunction Maria and Anna in the conjoined clause somehow inherits the distributivity so that it can get the interpretation that Maria and Anna each have registered their respective cars.

Turning now to indefinites appearing in totally unfocused shared constituents, we may state that the indefinite cannot have a specific reading and that there is no context in which it could be interpreted as denoting only one non specific subject.

(9) A: Wer hat wem ein Bild gezeigt? Who has who, Dat. a picture shown? 'Who showed a picture to whom?'

B: $\left[{ }_{F}\right.$ HANS $]$ hat $\left[_{F}\right.$ ANNA $]$ und $\left[_{F}\right.$ PAUL $]$ hat $\left[_{F}\right.$ FrIEDA $]$ ein Bild gezeigt. Hans has Anna, Dat. and Paul has Frieda, Dat. a picture shown. 'Hans showed Anna, and Paul Frieda, a picture.'

The only possible interpretation is that Hans showed some picture to Anna and that Paul showed some picture to Frieda. Both pictures can be referred to by a definite description like die Bilder (the pictures) in a sentence following (9)B such as By the way, Anna and Frieda liked the pictures. This means that the indefinite in an unfocused constituent can hardly serve as an antecedent for a pronoun as sie (they) like in Sie haben Anna und Frieda gefallen (Anna and Frieda liked them). And unlike the focused shared indefinite in (8), an unfocused shared indefinite cannot be coreferent with a singular pronoun in the scope of a plural set. 
Finally, it is worth pointing out that an unfocused indefinite which is in a shared constituent containing a focused constituent may have a unique and a distributive non specific reading.

(10) A: Wann hat Paul Anna und hat Hans Frieda ein Bild gezcigt? When has Paul Anna, Dat. and has Hans Frieda, Dat. a picture shown 'When did Paul show Anna, and Hans Frieda, a picture?'

B: Paul hat Anna und Hans hat Frieda [F am SONNTAG] ein Bild gezeigt. Paul has Anna, Dat. and Hans has Frieda, Dat. on Sunday a picture shown 'It was on Sunday that Paul showed Anna, and Hans Frieda, a picture'

The B-construction can be interpreted either as that Paul and Hans showed one non specific picture to Anna and Frieda on Sunday, or that they, on the same day, showed two non specific pictures.

To sum up, we may state that shared indefinite expressions found in a focused constituent may have both a specific and an non specific reading. The specific interpretation coincides with the reference to only one individual whereas the non specific interpretation is not restricted with respect to the distributive or unique reading. The non specific distributive or unique reading is also possible if the indefinite is non-focused and contained in a shared constituent which itself contains a focused constituent. On the other hand, indefinites in totally non-focused constituents can only have an non specific, distributive reading. Further, only indefinites found in focused shared constituents are accessible to pronouns whereas indefinites appearing in a non-focused shared constituent can only be coreferent with definite expressions.

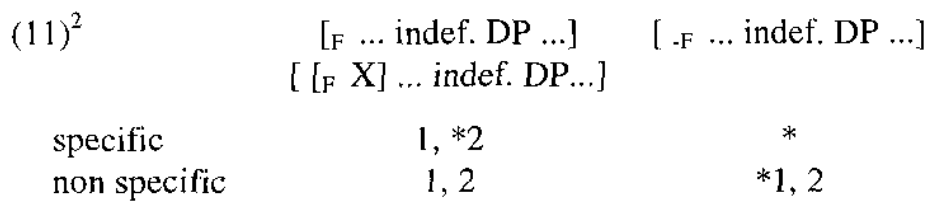

These observations raise questions like: First, why is the unique reading of the indefinite restricted to its being in a shared constituent which is either focused or contains a focused constituent? Second, why does the distributive reading coincide with non specific indefinites? Third, why do unfocused indefinites not allow a specific interpretation? And finally fourth, why do pronouns only have access to focused indefinites with a specific reading, whereas non specific indefinites can only be coreferent with definite expressions?

These questions raise considerations which we will deal with in the following. In Section Two, we will present the preliminaries for the explanation that the unique and the distributive reading depend on an information structure theory which demands that the conjuncts in coordination must be symmetric with regard to information structure. We will further see how information structure is anchored in syntax. Then, in section Three, we will sketch a theory of indefinites that is adequate for the referential behaviour of indefinites in shared constituents. And finally, because the referential behaviour of focused shared indefinites as well as number agreement and restrictions on anaphoric expressions in subsequent sentences will lead to the idea of a certain set formation, we will elaborate this idea with its semantic and syntactic consequences.

2 The numbers 1 and 2 label the unique and the distributive reading. 


\section{Information-Structural Symmetry in Coordination}

In this section we will set the preliminaries for an explanation for the variations in referential behaviour seen in focused and unfocused shared indefinites in coordinative structures and for the differing anaphoric expressions in subsequent sentences. As we will see in the next section, the unique interpretation of the focused shared indefinite is only possible if the constituent containing the indefinite is somehow beyond the actual coordination. This extraposition is derived by a principle which is independent of the interpretation of the indefinites. This principle, which results from Rooth's (1992) Theory of Focus Interpretation, demands that all conjuncts be parallel with regard to their information structure. ${ }^{3}$

The information structure of a sentence is regarded as the syntactically indicated information packaging of a sentence. Focus is realized by that accent which goes to the most accentuable syllable of the focus constituent, or in other words, to the focus exponent. The focus exponent is a syntactic $X^{0}$-category associated via focus projection with a focus feature. This focus feature is assigned freely to a syntactic constituent and thus forms a focus domain. While in the case of narrow focus the focus exponent and the focus domain match, where the focus is wide the focus feature projects to the focus exponent.

To come back to information structural symmetry in coordination, this means that the conjuncts match with respect to their background information and the number of their focused constituents. Each focused constituent in one conjunct corellates to a focused alternative in another conjunct. This parallelism follows from Rooth's theory, according to which each focus feature is interpreted at LF by a focus operator written . As for the examples mentioned here, the interpretation takes place at the level of the CP-node which is minimally dominating the focused constituent.

(12) $\left[_{C P}\left[[\text { HANS }]_{F} \text { schreibt }[\text { seiner MUTTER }]_{F} \text { einen Brief }\right]_{3} \sim \mathrm{p}_{4}\right]$ und Hans writes his mother a letter and

$\left[\mathrm{CP}\left[[\text { FRITZ }]_{\mathrm{F}} \text { Brief }[\text { seinem VATER }]_{\mathrm{F}}\right]_{4}-\mathrm{p}_{3}\right]$

Fritz writes a letter his father

'Hans is writing his mother, and Fritz his father, a letter.'

The focus operator has two arguments: the left one is the overt first conjunct Hans is writing a letter to his mother, and the second is non-overt and represented as a proposition variable $\mathrm{p}$. This variable corresponds to the other overt conjunct Fritz is writing his father a letter, which is coindexed with this corresponding proposition variable. The semantics of the focus operator introduces two conditions. The first one demands that the proposition of the conjunct serving as the instantiation of the proposition variable $p$ must belong to the same focus semantic value as the proposition of the conjunct which is the overt argument of the focus operator. The focus semantic value of a sentence is defined by Rooth as a set of propositions which is, informally speaking, derived from the semantic value of the sentence in such a way that the positions of the sentence occupied by focused constituents are substituted by variables. For both conjuncts in (12) the focus semantic value is therefore:

3 As to semantic parallelism in coordinative structures cf. Lang (1984). 
(13) i. \{write (x) (y) (a letter) / $x, y \in E\}$, with $E$ as individual domain ii. ' $\mathrm{x}$ write $\mathrm{y}$ a letter'

To prevent variables $\mathrm{x}$ and $\mathrm{y}$ from being instantiated identically in both conjuncts, the focus operator introduces a second condition. This condition demands that the instantiation of $\mathrm{p}$, namely the proposition of the other conjunct, differ from the overtly expressed proposition. This second condition is fulfilled by the different meanings of the focused constituents. Thus, just as the first conjunct serves as an alternative to the second, the second conjunct serves as an alternative to the first.

In demanding an alternative via the instantiation of the propositional variable $p$, the focus operator relates the overtly expressed proposition to the context, which should render at least one value for $\mathrm{p}$. The focus operator induces coordination if there is some need to express one or more alternatives. Further, in requiring identical non-focused parts of the conjuncts in coordination, the focus operator and/or the focus feature create semantic redundancy which can be avoided by ellipsis.

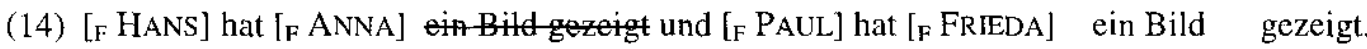
Hans has Anna, Dat. and Paul has Frieda, Dat. a picture shown. 'Hans showed Anna, and Paul Frieda, a picture.'

There are, however, cases which seem to contradict the focus semantic theory applied here. What we have in mind are constructions like (5), (8), (10), and (15).

(15) HANs hat ANNA und FRITZ hat PAula [F ein BILD gezeigt]

Hans has Anna, Dat. and Fritz has Paula, Dat. a picture shown

'Hans showed Anna, and Fritz Paula, a picture.'

If these constructions consisted merely of two conjuncts they would be asymmetric with regard to their information structure. Thus in (15) the first conjunct Hans hat Anna has two focused constituents, namely Hans and Anna, and the second conjunct Fritz hat Paula ein Bild gezeigt contains three focused constituents, Fritz, Paula and ein Bild gezeigt. Because both conjuncts differ with respect to their focus semantic values, such configurations should be ruled out. But these constructions are fully acceptable. It is therefore necessary to find a syntactic representation that fits the focus semantic theory. This can be achieved if we imagine the focused shared constituent ein Bild gezeigt as being beyond the actual coordination, see (16).

The coordination format here follows the ideas of Grootveld (1994) and te Velde (1996). Without going into detail, symmetric coordinative constructions are represented there in a third dimension, which is indicated here by dotted lines. Like Büring \& Hartmann (1998) and te Velde, we adjoin the coordination Phrase \&P to a constituent of the first conjunct. Here the coordination Phrase $\& \mathrm{P}$ is adjoined to $\mathrm{CP}_{1 \mathrm{a}}$ and thus creates $\mathrm{CP}_{1 \mathrm{~b}}$. Due to the threatening information structural mismatch, the focused constituent ein Bild gezeigt is beyond the actual coordination, i.e., beyond the so-called third dimension.

4 To simplify matters, we use (ii) as the representation of the focus semantic value. 
(16)

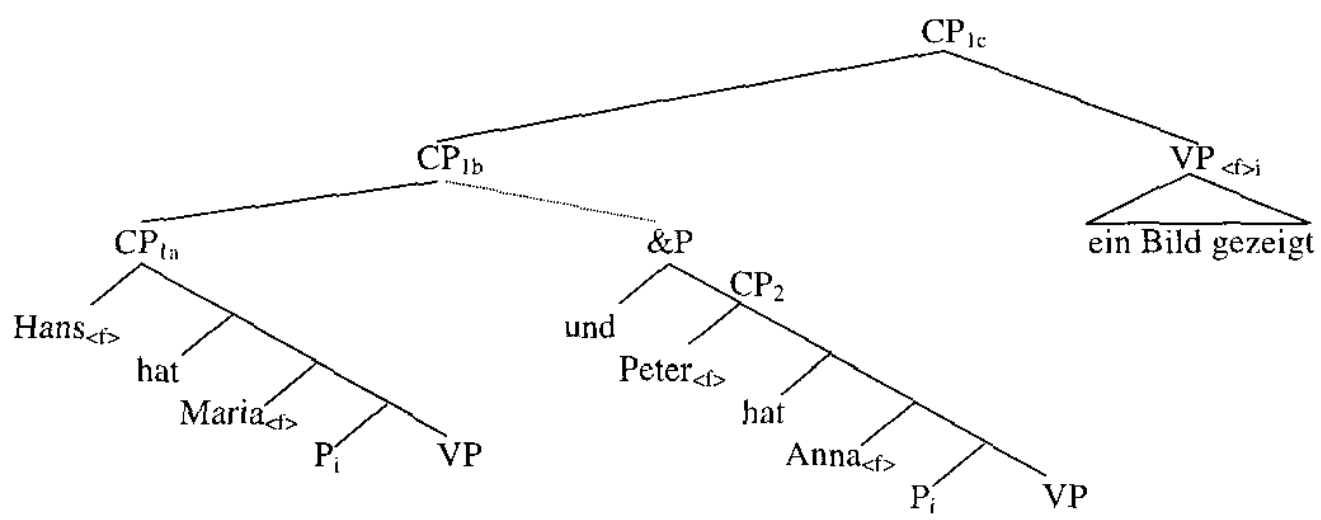

Let us now turn to the focus interpretation of (16) and there first to the focus interpretation of $\mathrm{CP}_{1 \mathrm{~b}}$. We will notice that it is well formed with regard to its focus structure. According to the focus interpretation theory, each conjunct shares the same focus semantic value and each conjunct renders alternative values for the variables in the focus semantic value - cf. (17).

(17)

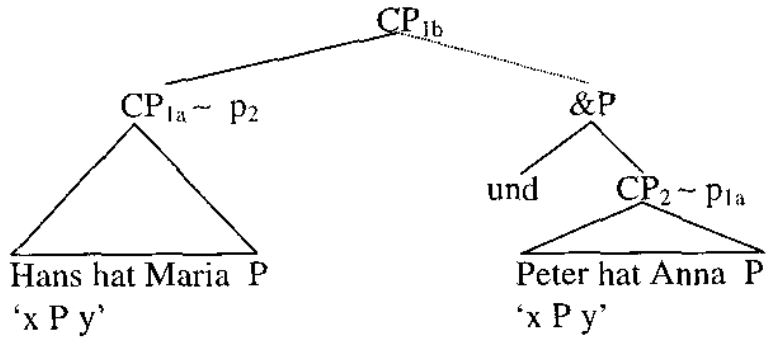

Proceeding to the focus interpretation of the whole construction as shown in (18), it should become clear that the actual coordination phrase $\mathrm{CP}_{1 \mathrm{~b}}$ can be seen as the background $(\mathrm{B})$ to the extraposed, focused VP. The latter is marked with a focus feature interpreted as a focus operator in $\mathrm{CP}_{\mathrm{fc}}$, the upmost node of the construction.

(18)

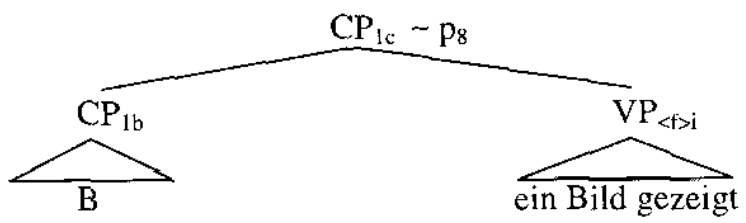

As we may remember, the focus operator demands an instantiation for its second argument-here the proposition variable $\mathrm{p}_{8}$-that differs from the semantic value of $\mathrm{CP}_{10}$. Because the instantiation of $p_{8}$ is not expressed within the construction, it must be found in the preceding or subsequent discourse. Imagine a discourse where the following sentence could be a suitable alternative to (18):

(19) Sie haben ihnen [cinen FREUND vorgestellt $]_{\mathrm{F}}$ They have them, Dat. a friend, Acc. introduced 'They introduced a friend to them.' 
Here the focused VP renders an alternative to the focused VP in (18). As we have seen, constructions like (18) on the one hand contain coordinated phrases which are mutual alternatives, and, on the other, behave like configurations which do not contain coordination because the coordinate phrase serves as the background to a focused VP. The alternative to the whole construction must be found in the discourse. In contrast to this extrapositional construction type, coordinations where the shared constituent is unfocused, do not require the shared constituent to escape the actual coordination. These constructions can be represented syntactically as ellipses. In the following, we will see that we need the extrapositional construction type to explain the referential interpretation of shared indefinites as well as the type of anaphoric expressions corresponding to them.

\section{Indefinites in Extraposition and Ellipsis}

\subsection{Preliminaries}

The theory of indefinites used here should serve serveral purposes. First and foremost, it should be able to explain the referential behaviour of indefinites in shared constituents as well as their sensitivity towards focusation. Second, it should be appropriate for all uses of indefinites including their 'scopal' properties. Third, it should explain the similarities and differences between indefinite and definite descriptions. Fourth, it should account for the capacity of indefinites to change the context. And fifth, it should, if possible, render only one lexical entry for all uses of indefinites and not repeal syntactic restrictions. The theory which seems best suited to serving all these purposes is the one elaborated by Heusinger (1997), who, like Winter $(1996,1997)$ and to some extent Reinhart (1995b, 1997), considers indefinites to be individual terms. In contrast to the pure quantificational approaches, where all indefinites are represented as existential generalized quantifiers, this theory may explain all scopal properties of indefinites and does not cancel syntactic island constraints because it manages without quantifier raising. ${ }^{5}$ Compared to approaches anchored in dynamic semantics, where indefinites are treated as free variables over individuals in the extension of the N'-predicate, Heusinger's theory allows us to deduce a lexical entry for indefinites. And unlike the mixed approaches, where indefinites are thought to be both existential generalized quantifiers and individuals - cf. Fodor \& Sag (1982) and Reinhart (1995b), this theory may provide a unified lexical semantic representation for indefinites, thus avoiding lexical ambiguity. ${ }^{6}$ Finally, with this theory we may explain the focus sensitivity of indefinite expressions, i.e., their different referential properties depending on whether or not they are focused.

\footnotetext{
5 For a discussion of indefinites as existential generalized quantifiers or individuals sec Reinhart (1995b), Winter (1995) and Heusinger (1997).

6 Discussing Reinhart (1995a), Winter (1995) shows that there is no need for her mixed approach in treating idefinites as individual terms represented as a variables over choice functions that can be existentially quantified anywhere, and in attaching a distributive operator to plural sets.
} 
Following Heusinger (1997), we regard both indefinite and definite descriptions as indexed epsilon terms ' $\varepsilon_{\mathrm{i}} \mathrm{x}$ Px'. They consist of the description $\mathrm{P}$, the referential variable $\mathrm{x}$, the epsilon operator $\varepsilon$ indexed with a context index variable $\mathrm{i}$, which denotes a situation. Each situation is characterized by a salience hierarchy, i.e. by a ranking among subjects of the same sort. The epsilon operator is interpreted as a choice function which selects a subject from the context. ${ }^{7}$ The idea of interpreting indefinite expressions as choice functions, also found in Reinhart (1995b) and Winter (1996), traces back to Hilbert's program to eliminate quantificational mechanisms from logic (Hilbert \& Bernay (1939)).

The subject chosen by the choice function must somehow be embedded in the context. If we distinguish between the speaker's context and the common discourse context, it must be possible to anchor the subject selected by the choice function at least in the speaker's context. ${ }^{8}$ As for definite expressions, they express that the subject they denote is already anchored in the common discourse context, and anchored there as the most salient subject having the description P. This is represented in that the epsilon operator has a context index which denotes a certain salience hierarchy. Being anchored in the context and linked to a salience hierarchy as the most salient subject, the subject can be identified with an individual.

Indefinites, on the other hand, express that the subject chosen by the choice function is independent from a certain salience hierarchy. Thus if the context index variable $i$ is not bound by another operator, it must be existentially quantified. Being bound by an operator means that the subject is not anchored in the common discourse context. It is this status of being or not being contextually anchored that distinguishes definite and indefinite descriptions linguistically. That context subjects are not anchored by indefinite expressions does not mean that they may not get anchored at all. Indeed, they must be anchored if a subject is to serve as a topic in the following discourse. The subsequent text may then specify them more and more until they are specific enough to be identified with an individual. Another need for the subject's context anchoring arises if it can be identified with an individual given by the situational utterance context. In this case the subject cannot escape from being anchored in this context. This is what may be called the deictic use of an indefinite. That the subject denoted by the indefinite is anchored in the situative context is formally expressed in that the context index variable is substituted by the index denoting the salience hierarchy given by the situational context.

If a subject is anchored in the context as the most salient subject, it may be referred to by a pronoun. Following Heusinger (1997:161ff.) again, pronouns are considered here to be epsilon terms like definite and indefinite expressions, but lacking a description. What further distinguishes pronouns from indefinite expressions, is that their epsilon operator has a context index. This means that the pronoun, like a definite expression, picks up the most salient contextually anchored subject. Being referred to by a pronoun, the subject denoted by the indefinite gets anchored as the most salient subject in the context. In this role, the indefinite contributes to the modification of a

7 Following Dekker (1997), we use the term 'subject' to refer to epistemic representatives of individuals. Whereas individuals exist in the world and are therefore total objects, subjects are partial objects because the entity they represent need not be identified. They may, however, become total objects and at which point they correspond to real individuals.

8 Cf. the licensing definition in Dekker (1997) and (1999). 
given salience hierarchy, i.e. the context index $i$ is extended to $i^{*}$. If the pronoun refers to this subject, the pronoun's context index is identical with $i^{*}$.

In that, on the one hand, the indefinite expresses that the subject chosen by the choice function is not anchored in the common discourse context and that, on the other, the subject may become anchored by some discourse need or even must be anchored because of a situatively given individual, we get the impression that the indefinites introduce new context anchored subjects. But what indefinites really do is enable the anchoring of new subjects in the context and the change of a given salience hierarchy. Whether or not these subjects are anchored is dependent on the discourse. ${ }^{9}$

Subjects need not be anchored if they are not relevant for the discourse. Then, they may disappear from the discourse. Moreover, subjects may even be blocked from being anchored. This happens when they are in the scope of a quantifier which has some distributing force. Subjects that are not anchored cannot be further specified and identified with an individual, and they cannot be referred to by pronouns because pronoun coreference requires an anchored subject.

Saying that an indefinite is underspecified with regard to the ability or inability of the subject it denotes to be anchored in the context, is only sensible if the subject has not been anchored there before. The subject must be new, at least for the recipient of the utterance. From this it follows that the indefinite expression must be contained in a constituent representing presentational or new information focus. Conversely, it is only when the indefinite is included in a presentational focus constituent that the subject it denotes may be anchored. ${ }^{10}$ That it need not be anchored has already been seen.

Thus arises the question how to explain an indefinite which is not in a focused constituent. Recall that the genuine meaning of an indefinite is that the subject it denotes is not anchored in the context. Being unfocused, and therefore in the background, the indefinite tells us that the subject denoted by it was not previously anchored and it reveals why this is so. As the reasons for not being anchored are still alive, the subject denoted by an unfocused indefinite cannot for the time being be anchored. This is what creates the seeming incapability of unfocused indefinites to anchor new discourse subjects. Metaphorically speaking, unfocused indefinites are second-hand indefinites in that they again denote an non specific, not anchored subject. "

Saying that unanchored subjects do not create discourse objects and therefore can hardly be referred to by pronouns - cf. (20.i) - does not mean that these subjects are lost forever. They can be retrieved by topicalization. This may happen, for instance through the use of a definite expression - cf. (20.ii).

(20) i. First every child read a book and then one child talked about*them.

ii. First every child read a book and then, one child talked about the books.

\footnotetext{
9 Reinhart (1997:388) also points out that discourse properties are not coded in the syntax (or formal semantics) of indefinites but that the latter enable certain discourse uses.

10 This correlates to Ekkardt's (1996) 'Existential Focus Hypothesis' that an indefinite is interpreted existentially iff it is in the presentational focus domain and generically if it is outside this domain.

${ }^{11}$ Krifka (1998:1) introduces the term 'non-novel indefinites' to relate to indefinites, which “... presuppose their discourse referents".
} 
What happens here is that the definite expression the books in (ii) denotes a subject which is a set of books and which must be anchored in the context. Of course, this subject was not anchored by the indefinite expression a book in the foregoing sentence. Instead, the set is formed by the non specific subjects corresponding to each patient of the reading events. In that this set can become a topic through the use of the definite expression, we may say that the definite expression topicalizes a non-contextually anchored subject and makes it contextually anchored. ${ }^{12}$

To repeat, indefinites are non specific per se in that they denote subjects which are not anchored in the previous context. If these subjects get anchored, which is only possible if the indefinite is in focus, they are then added as new subjects to the context. These new contextually anchored subjects can serve as a topics and may thus be referred to by pronouns. Because they can be anchored, and thus referred to, we can say that the indefinite has a specific use. If the subject the indefinite denotes, is not anchored, the use of the indefinite is non specific. Unfocused indefinites are always non specific because they denote subjects which for some particular reason were not previously anchored.

\subsection{Indefinites in Extraposition}

Having outlined the fundamentals, we may now turn to the interpretation of shared indefinites. Disregarding the information structure for the time being, we can see that an ellipsis like (21), has the same semantic form as the corresponding extraposition structure as in (22) - cf. (21.ii) and (22.iii). Without going into detail, the omitted constituent in the ellipsis construction is interpreted here as a copy of its antecedent.

(21) i. [Hans $\mathrm{F}_{\mathrm{F}}$ hat Maria $\mathrm{F}_{\mathrm{F}}$ ] und [Paul $\mathrm{F}_{\mathrm{F}}$ hat Anna $\mathrm{F}_{\mathrm{F}}$ ein Bild gezeigt] Hans has Maria, Dat. a picture shown and Paul has Anna, Dat. a picture shown 'Hans showed Maria, and Paul Anna, a picture.'

ii. Show (hans)(maria) $\varepsilon_{\mathrm{j}} \times$ Picture(x) \& Show (paul)(anna) $\varepsilon_{\mathrm{j}} \mathrm{x}$ Picture( $\mathrm{x}$ )

(22) i. [Hans hat Maria $P_{i}$ und Paul hat Anna $\left.P_{i}\right]\left[{ }_{F} \text { ein Bild gezeigt }\right]_{i}$

ii. $\lambda \mathrm{P}[\mathrm{P}(\mathrm{h})(\mathrm{m}) \& \mathrm{P}(\mathrm{p})(\mathrm{a})] \quad \lambda \mathrm{y} \lambda \mathrm{z}\left[\operatorname{Show}(\mathrm{z})(\mathrm{y}) \varepsilon_{\mathrm{i}} \mathrm{x} \operatorname{Picture}(\mathrm{x})\right]=$ iii. Show (hans)(maria) $\varepsilon_{\mathrm{i}} \times$ Picture $(\mathrm{x}) \&$ Show (paul)(anna) $\varepsilon_{\mathrm{i}} \mathrm{x} \operatorname{Picture}(\mathrm{x})$

Because the context index variables must be existentially quantified, they can either be bound by the same operator as in (23.i) or bound by an own operator - cf. (23.ii).

(23) i. $\exists i\left[\right.$ Show $(h)(m) \varepsilon_{i} x \operatorname{Picture}(x) \&$ Show (p)(a) $\left.\varepsilon_{j} x \operatorname{Picture}(x)\right]$

ii. $\exists i\left[\operatorname{Show}(\mathrm{h})(\mathrm{m}) \varepsilon_{\mathrm{i} x} \operatorname{Picture}(\mathrm{x})\right] \& \exists \mathrm{i}\left[\operatorname{Show}(\mathrm{p})(\mathrm{a}) \varepsilon_{\mathrm{i}} \mathrm{x} \operatorname{Picture}(\mathrm{x})\right]$

Recalling the data from Section One which described the variant types of referential behaviour shown by indefinites in coordination, we may state that (23.i) seems to be appropriate for the construction with the unique reading of the indefinite and that (23.ii) gives us the distributive reading. What is not clear, however, is how we may arrive at these two versions from the identical representations (21.ii) and (22.iii).

${ }^{12}$ Concerning the various access routes of pronouns and definite expressions to their antecedents, compare Reinhart's accessibility theory (Reinhart (1995b)). 
This forces us to include the focus semantic interpretation in the semantic interpretation of indefinites in structures like (21) and (22). Lets us first turn to the so-called extrapositional structures, as in (22.i), where the indefinite expression is included in a focused constituent. Recall that in Section Two we regarded the actual coordination as the background with regard to the extraposed constituent (the constituent standing apart). As we may see in example (22.ii), the background does not contain an indefinite expression and therefore it is not presupposed that the indices of the epsilon terms in (22.iii) are each bound by an existential quantifier. The background character of the actual coordination thus prevents a representation like (23.ii). The only possibility is that the existential operator has the whole coordinative expression in its scope, as in (23.i), repeated here as (24):

(24) $\exists i\left[\operatorname{Show}(h)(m) \varepsilon_{\mathrm{i}} \mathrm{x} \operatorname{Picturc}(\mathrm{x}) \& \operatorname{Show}(\mathrm{p})(\mathrm{a}) \varepsilon_{\mathrm{i}} \mathrm{x} \operatorname{Picture}(\mathrm{x})\right]$

This is exactly the form we need to interpret the indefinite expression as being capable of denoting one subject that can be anchored in the context. This is what we in Section One called the unique denoting of the indefinite. If the subject gets anchored in the context, it becomes specific and can be referred to by a pronoun as we observed in Section One with regard to (5)B:

(25) B: Hans hat Anna und Paul hat Frieda [F ein Bild gezeigt]

Hans has Anna, Dat. and Paul has Frieda, Dat. a picture shown

'Hans showed Anna, and Paul Frieda, a picture.'

Es war von Picasso.

It was by Picasso.

In Section One, focused indefinites were considered to be either specific or non specific. Building on the prerequisites given in paragraph 3.1, we may now be more precise. Focused indefinites are non specific, per se, but allow an non specific or a specific reading depending on the context. The latter case presupposes that the subject denoted by the indefinite gets anchored in the context. This, as in (25), can be witnessed by a coreferential pronoun. If, on the other hand, the subject denoted by the indefinite is not relevant for the further discourse so that there is no need for it to be anchored, the indefinite remains non specific. This can be shown by the B's-sentence of example (10) in Section One repeated as (26)B if we imagine the sequence (26) as a continuation of (22).

(26) A: [F Wann] hat Hans Maria und hat Paul Anna ein Bild gezeigt?

When has Hans Maria, Dat. and has Paul Anna, Dat. a picture shown

'When did Hans show Maria, and Paul Anna, a picture?'

B: Hans hat Maria und Paul hat Anna [F am Sonntag] ein Bild gezeigt. Hans has Maria, Dat. and Paul has Anna, Dat. on Sunday a picture shown 'Hans showed Maria, and Paul Anna, a picture on Sunday.'

Turning to the so-called non specific, distributive reading of focused shared indefinites, which was observed in the first Section, the question arises how such a reading can be derived from a representation like (24), which was said to be the only possible one for extrapositional structures. 


\subsection{The Idea of Set Formation in Coordination}

We enter this section with the unsolved question of how to derive the distributive reading of focused shared indefinites in constructions like (22) or (24). Being extrapositional constructions with the indefinite expression beyond the actual coordination, the context indices given by the semantics of the indefinite cannot be bound by two existential operators each having one conjunct in its scope. Now it is not only the need for the derivation of the distributive reading of focused shared indefinites but also other pieces of evidence that force us to reconsider the semantic representation of extrapositional structures like (22).

What we have in mind is first the behaviour of pronouns towards contextually anchored subjects being denoted by expressions in the so-called actual coordination. Notice in the following example that the singular possessive pronoun contained in the shared focused constituent can hardly refer to any contextually anchored subject denoted by the syntactic subjects in the actual coordination.

(27) Hans $s_{\mathrm{i}}$ hat Anna und Fritz $\mathrm{j}_{\mathrm{j}}$ hat Paula $\left[\operatorname{sein}_{*_{\mathrm{i} / *_{j} / k} B I L D} \text { gezeigt }\right]_{\mathrm{F}}$. Hans has Anna, Dat. and Fritz has Paula, Dat. his picture shown 'Hans showed Anna, and Fritz Paula, his picture.'

What prevents the sloppy reading in (27) is that the possessive expression is contained in a focus phrase that is beyond the actual coordination. We already know the reasons for the position of the shared focus phrase. Recall that within the framework of the focus interpretation theory, the focus phrase should have a focused pendant in the first conjunct. This, however, is not the case. The focus phrase must therefore be beyond the actual coordination. Being thus in extraposition, the possessive pronoun can only refer to a contextually anchored subject which is not denoted by either syntactic subject of the actual coordination.

If, on the other hand, the shared constituent is not focused, there is no need for extraposition and sloppy identity now becomes possible. ${ }^{13}$

(28) $\left[\text { HANS }_{\mathrm{i}}\right]_{\mathrm{F}}$ hat $[\mathrm{ANNA}]_{\mathrm{F}}$ und $\left[\mathrm{FRITZ}_{\mathrm{j}}\right]_{\mathrm{F}}$ hat $[\text { PAULA }]_{\mathrm{F}}$ sein $\mathrm{n}_{\mathrm{j} / \mathrm{k}}$ Bild gezeigt. Hans has Anna, Dat. his picture shown and Fritz has Paula, Dat. his picture shown 'Hans showed Anna, and Fritz Paula, his picture.'

It is, however, possible to substitute a plural possessive pronoun for the singular pronoun in (27).

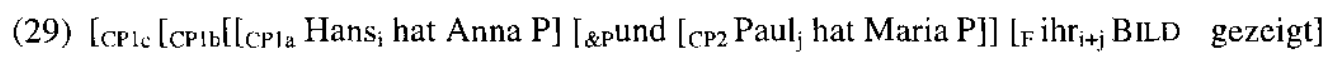
Hans has Anna, Dat. and Paul has Maria, Dat. their picture shown 'Hans showed Anna, and Paul Maria, their picture.'

From this we may conclude that the agents somehow form a set to which the plural pronoun can refer. This set formation of the agents prevents the singular possessive pronoun in (27) from referring to one of the agents in the coordinative construction. The next example also shows that a plural pronoun in the focused shared constituent refers to a set which is now formed by the subjects denoted by the syntactic objects Anna and Maria.

${ }^{13}$ For a more detailed analysis of sloppy identity cf. Tancredi (1992). 
(30) $\left[\mathrm{CP}_{1 c}\left[\mathrm{CP} 1 b\left[\left[_{\mathrm{CP} 1 a}\right.\right.\right.\right.$ Hans hat Anna $\left.{ }_{i} \mathrm{P}\right]\left[_{\& \mathrm{P}}\right.$ und [CP2 $_{\mathrm{Caul}}$ hat Maria $\left.\left.{ }_{\mathrm{j}} \mathrm{P}\right]\right]$

Hans has Anna, Dat. and Paul has Maria, Dat.

[F überredet, daß sie $_{i+j}$ mit ins KINO gehen]]

persuaded that they along to the movies go

'Hans has persuaded Anna, and Paul Maria, that they should go along to the movies.'

Once again, a sloppy reading is only possible if the shared constituent is not focused.

(31) [CPIb [CPla HANS hat $\mathrm{ANNA}_{\mathrm{i}}$ überredet, daß sie $\mathrm{Si}_{\mathrm{j}}$ mit ins Kino geht]

Hans has Anna, Dat. persuaded that she along to the movies, $\mathrm{Sg}$. go

[\&P und [CP3 PAUL hat MARIA $\mathrm{j}_{\mathrm{j}}$ überredet, daß $\mathrm{sie}_{\mathrm{j}}$ mit ins Kino geht]]]

and Paul has Maria, Dat. persuaded that she along to the movies, Sg. go

'Hans has persuaded Anna, and Paul Maria, that she should go along to the movies.'

Here the focus interpretation theory allows for the shared constituent to stay in the coordinative phrase and to have an elliptical pendant.

Now let us turn to another piece of evidence supporting extrapositional constructions with shared focused constituents and the idea of set formation. If in the German coordinated subordinate clauses the VP is focused, the finite verb may agree in number with the set of agents provided these are in the background coordinate phrase.

(32) Bist du sicher, daß Hans den Saft und Fritz den Wein GESTOHLEN haben?

Are you sure that Hans the juice, Acc. and Fritz the wine, Acc. stolen have, Pl.?

'Are you sure that Hans STOLE the juice and Fritz the wine?'

Ich glaube eher, daß Hans den Saft und Fritz den Wein [F GEKAUFT haben]

I believe rather that Hans the juice and Fritz the wine bought have, PI.

'I rather believe that Hans BougHT the juice and Fritz the wine.'

This example shows that the subjects denoted by the syntactic subjects Hans and Fritz. form a set with which the verb morphology agrees in number. If, on the other hand, the VP is not focused, extraposition is not necessary, so that ellipsis in the first conjunct is allowed. Set formation of the agents of the conjuncts does not happen, and in each conjunct the verb agrees in number with the singular syntactic subject.

(33) Bist du sicher, daß HANS BIER und FRITZ WEIN gekauft hat?

Are you sure that Hans beer, Acc. and Fritz wine, Acc. bought has, Sg.?

'Are you sure that Hans bought beer and Fritz wine?'

$\mathrm{Na}$, ich glaube eher, daß HANS SAFT und FRITZ MLCH gekauft hat.

Well,I believe rather that Hans juice bought has, Sg. and Fritz milk bought has, Sg.

'Well, I rather believe that Hans bought juice and Fritz milk.'

Pursuing the question of pronoun interpretation and number agreement has led us to the idea that both the agents and the patients in constructions like (29), (30) and (32) each form a set. But how should we construe this set formation? Consider, for instance, example (29), repeated as (34):

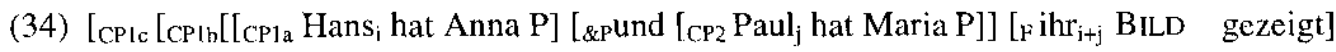
Hans has Anna, Dat. and Paul has Maria, Dat. their picture shown 'Hans showed Anna, and Paul Maria, their picture.' 
We have in the actual coordination, $\mathrm{CP}_{1 \mathrm{~b}}$, two sets, one containing the individuals Hans and Paul and the other containing Anna and Maria. This means that there are two possible ways of interpreting the actual coordination. The first one relates to a set of the pairs $<$ hans, anna $>$ and $<$ paul, maria $>$. Then this interpretation is converted into a pair of two sets. $<\{$ hans, paul $\},\{$ anna, maria $\}>$. It is important to point out that the derivation of the pair of sets is only possible if the coordinative phrase in which it is contained is background. With this information structural status, it is no longer relevant which agent is related to which patient.

Now there are at least three things which have to be shown. First, what is the semantic mechanism that enables the derivation of the set formation of agents and patients from the set of pairs? Second, how is it possible to keep the pair-of-setinterpretation transparent vis-à-vis the set-of-pairs-interpretation? It is essential that the pair-of-set-interpretation not be allowed to correspond to the pairs $<\mathrm{Hans}$, Maria $>$ and $<$ Paul, Anna $>$. The pair-of-set-representation as well its transparency vis-à-vis the setof-pairs-representation are still under consideration, so that no conclusive statement is possible here. ${ }^{14}$ Assuming set formation of the agents on the one hand and of patients on the other, we seem to be on the right track. This becomes obvious when we recall the coreferential behaviour of pronouns and the number agreement of sentence final verbs with respect to the syntactic subjects in the actual coordination, which in turn must be background. We will see below that set formation is useful in attaining the distributive reading of an indefinite expression contained in the shared focused constituent.

The third challenge concerns the syntactic representation of the so-called extrapositional construction. As you might remember it was thought to be a construction consisting of conjoined clauses each containing a trace of the extraposed focused shared constituent. The traces were interpreted as a variable $\mathrm{P}$ - cf. (16). With this syntactic representation, the conjuncts are conjoined propositions. But what we need are conjoined pairs or a pair of conjoined sets. One possible way to represent this in the generative syntactic framework used here would be to take the expression 'shared constituent' literally. This is accounted for by a syntactic representation for shared constituents recently elaborated by Wilder (1998) according to which identical constituents may merge under certain syntactic conditions. Adopting this idea to constructions like (22), we get the following syntactic representation: ${ }^{15}$

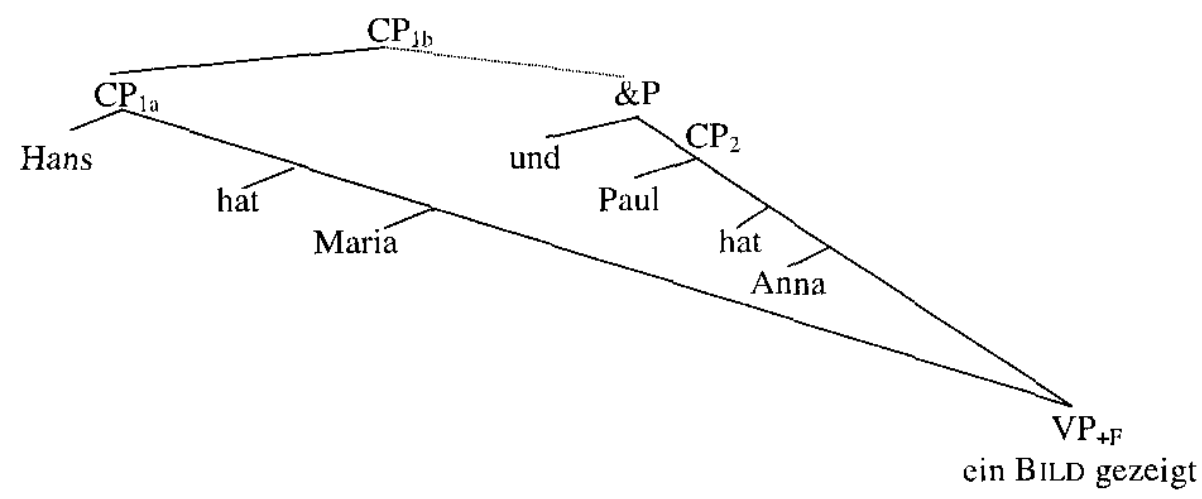

${ }^{14}$ An access to create a formalism which can manage this problem has been pointed out to me by $\mathrm{R}$. Naumann (p.c.).

15 Notice that the syntactic representation deviates from Wilder's idea in the coordination of $\mathrm{CP}_{1 \mathrm{a}}$ and \&P. He doesn't assume a third dimension and for him the first conjunct is in the Spec-position of the conjunction and the second conjunct is the complement of the conjunction head. 
It seems feasible to show that this representation is in agreement with the focus semantic theory by observing that conjuncts $\mathrm{CP}_{1 \mathrm{a}}$ and $\mathrm{CP}_{2}$ may serve as alternatives, that they share the same focus semantic value, and that the focus feature of the VP is interpreted in $\mathrm{CP}_{\mathrm{jb}}$. Thus the focus operator need not find the instantiation of the variable within the coordination, but may find it beyond the entire construction - cf. (19).

Leaving the syntactic representation aside and looking at its semantic interpretation, we realize that the shared predicate can be applied to its agent and patient argument only if the agents and the patients of the conjuncts each form a set.

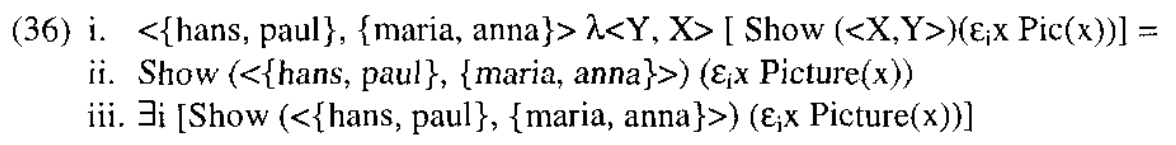

If the context index is bound by the existential operator, as in (36.iii), we get a semantic form which allows both the specific and the non specific, unique reading. This form corresponds to (24), which we obtained without set formation. Remember here that the need for set formation is due to the derivation of the distributive reading of the indefinite, the referential behaviour of pronouns, and the plural number agreement in German verb final clauses.

Let us now turn finally to the distributive reading of indefinites in focused shared constituents. With regard to example (22) this reading indicates that one picture was shown to Maria while another picture was shown to Anna. This distributive reading could also be gained by an overtly expressed distributive operator such as jeweils $(e a c h)$.

(37) Hans hat Maria und Paul hat Anna jeweils ein Bild gezeigt.

Hans has Maria, Dat. and Paul has Anna, Dat. each a picture shown

'Hans showed Maria, and Paul Anna, a picture each.'

(38) Hans und Paul haben (jeweils) Maria und Anna (jeweils) ein Bild gezeigt. Hans and Paul have each Maria, Dat. and Anna, Dat. cach a picture shown 'Hans and Paul each showed a picture to both Maria and Anna.'

In both cases the distributive operator induces two events with each event being assocjated with one patient of the set of patients and with one agent of the set of agents. As we know, this distributive reading can also be achieved without this overt operator. This could be managed by introducing a covert distributing operator attached to the pair of sets. The idea of such covert operators can be traced to Lasersohn (1995) and Winter (1996:21ff., (1997:414ff.)). These authors differ in their views as to what the operator is associated with: Lasersohn argues that it is associated with the verb while Winter claims that it is associated with an individual plural set.

(39) i. Three boys ate a cake.

ii. $\exists f\left[C H(f) \wedge(f(\mathbf{3} \text { boys' }))^{D}([[\right.$ ate a cake $\left.]])\right]$

Without tackling Lasersohn's and Winter's diverging views, we apply the distributive operator to the pair of sets in (37).

(40) $(<\{\text { hans, paul }\}\{\text { maria, anna }\}>)^{D}$ Show $\left(\varepsilon_{\mathrm{j}} \mathrm{x} \operatorname{Picture}(\mathrm{x})\right)$ 
Let us now compare (40) with (36.iii) repeated here as (41), which does not have this operator.

(41) $\exists i\left[(<\{\right.$ hans, paul $\},\{$ maria, anna $\}>)$ Show $\left(\varepsilon_{i} x\right.$ Picture $\left.\left.(x)\right)\right\}$

Recall that this representation mirrors the uniqueness reading of the indefinite expression. Within this interpretation, one event is focused in which two sets and one picture are involved. By contrast, representation (40) indicates that there are two events with each event being associated with a pair consisting of one agent and one patient. From this it follows that two pictures are shown. The functioning of the distributive operator attached to the pair of sets is to be seen in connex with the set-of-pair-interpretion of the actual coordination so that the pair-of-set-interpretation must be transparent vis-à-vis the set-of-pair-interpretation. Thus the application of the distributive operator to the pair of sets yields the interpretation that Hans showed a picture to Mary and that Paul showed a picture to Anna.

Focused shared indefinites contained in the scope of a distributive operator, as in (40), have an non specific reading because the operator elicits as many context subjects as there are pairs distributed by it. These subjects cannot be anchored and therefore cannot be referred to by a pronoun in the subsequent discourse. But as we have already seen with regard to (20), the non-anchored subjects may form a set which becomes anchored and topicalized when picked up by a definite expression like die Bilder (the pictures) - cf. (42).

(42) i. Hans hat Maria und Paul hat Anna [F ein BILD gezeigt]. Hans has Maria, Dat. and Paul has Anna, Dat. a picture shown. 'Hans showed Maria, and Paul Anna, a picture.'

ii. Maria und Anna haben die Bilder sofort skizziert. Maria and Anna have the pictures at once sketched 'Maria and Anna sketched the pictures at once.'

Notice that if the focused shared constituent contains a singular possessive pronoun and if the focused shared constituent is distributed by an overt distributing operator as jeweils/each, the pronoun may be coreferent with a syntactic subject each.

(43) Hans $s_{i}$ hat Maria und Paul ${ }_{j}$ hat Anna ${ }_{F}$ jeweils sein ${ }_{\mathrm{i} ; \mathrm{j}}$ BLD gezeigt]. Hans has Maria, Dat. and Paul has Anna, Dat. each their picture shown. 'Hans showed Maria, and Paul Anna, his picture each.'

If, on the other hand, the focused shared constituent contained a plural possessive pronoun, the focused shared constituent would also be distributed in that there were two picture showing events. But what is not distributed is the set of Hans and Paul which either owns the two pictures or is the content of each picture.

(44) Hans $_{j}$ hat Maria und Paul ${ }_{j}$ hat Anna [F jeweils ihr $r_{j+j}$ BILD gezeigt]. Hans has Maria, Dat. and Paul has Anna, Dat. each his picture shown. 'Hans showed Maria, and Paul Anna, their pictures each.' 
Let us finally come back to examples like (8), where the pronoun is not coreferent with a context-anchored subject.

(45) Hans hat Maria und Paul hat Anna [F ein AUTo gekauft] und Maria und Anna Hans has Maria, Dat. and Paul has Anna, Dat. a car bought and Maria and Anna haben es gleich ANGEMELDET, have it at once registered

'Hans bought Maria, and Paul Anna, a car, and Maria and Anna registered it at once.'

Here, the indefinite is supposed to have a distributive reading. This kind of constructions corresponds to so-called paycheque-sentences - cf. Chierchia (1992) and Heusinger (1997:168). There, the pronoun is considered to denote a subject that is determined by a salient relation. According to Heusinger, the relation is expressed by the epsilon term in the antecedent clause and picked up by the pronoun in the subsequent sentence. To get a distributive reading in the second conjunct, a distributing operator must be attached to the set denoted by the conjunction Maria and Anna.

\subsection{Indefinites in Ellipsis}

In Section One it was observed that indefinites in unfocused shared constituents display a distributive reading only. Section Two then showed that such constructions may be represented as the coordination of two clauses with the second one containing the overtly expressed 'shared constituent' and the first containing the phonologically empty pendant. This phonological emptiness is possible because the deleted constituent and its overtly expressed pendant belong to the background. Having familiarized ourselves with the semantics of indefinites and with what may happen when they are in a focused constituent and what cannot happen when they are in background, we are now in a position to explain why indefinites in unfocused shared constituents always presuppose a distributive reading. Imagine a conversation between $\mathrm{A}$ and $\mathrm{B}$ :

(46) A: i. Yesterday, the painting class, which consists of Maria, Anna, Hans, and Paul, was in the National Galery.

ii. The teacher asked each boy to show a girl a PICTURE.

Now B is not so much interested in the pictures but in the 'explaining events' and asks A:

B: iii. Do you still remember WHO showed WHOM a picture?

A: iv. $[\mathrm{HANS}]_{\mathrm{F}}$ hat $[\mathrm{MARIA}]_{\mathrm{F}}$ und $[\mathrm{PAUL}]_{\mathrm{F}}$ hat $[\mathrm{ANNA}]_{\mathrm{F}}$ ein Bild gezeigt.

Hans has Maria, Dat. and Paul has Anna, Dat. a picture shown

'Hans showed Maria, and Paul Anna, a picture.'

What is going on here is that sentence (ii) contains an indefinite expression which denotes a subject (a picture) and which appears in a focused constituent. If B interprets (ii) in such a way that the indefinite is in the scope of the distributing operator each, the indefinite gets a distributive reading. With this reading, the subjects denoted by the indefinite are not anchored in the context and therefore B cannot use an anaphoric 
pronoun in his question (iii). Instead, he has to use a so-called second-hand indefinite. If, on the other hand, B had interpreted the indefinite in (ii) as not being distributed but as referring uniquely, he would have used a pronoun in his question, as in Do you still remember who showed it to whom? This shows that a subject denoted by an indefinite is anchored automatically if it is referred to by a pronoun, but must be picked up by an indefinite again if its non-anchored status is to be expressed. The need to express that the subject is not anchored results from the foregoing context (ii), which puts it in the scope of a distributive operator. It is thus presupposed that the unfocused indefinite gets a distributive reading. This reading implies that there are two events, each consisting of an agent, a patient and a theme. As to sentence (iv), the distributive reading can be represented as the conjunction of two propositions, each containing an epsilon term, the indices of which are existentially quantified by their respective operators.

(47) $\exists i\left[\operatorname{Show}(\mathrm{h})(\mathrm{m}) \varepsilon_{\mathrm{i}} \mathrm{x} \operatorname{Picture}(\mathrm{x})\right] \& \exists i\left[\operatorname{Show}(\mathrm{p})(\mathrm{a}) \varepsilon_{\mathrm{i}} \mathrm{x} \operatorname{Picture}(\mathrm{x})\right]$

This semantic representation of (46.iv) can now be syntactically represented as ellipsis:

(48) [ [HANS $]_{F}$ hat $[\text { MARIA }]_{F}$ und $\left[[\text { PAUL }]_{F}\right.$ hat $[\text { ANNA }]_{F}$ ein Bild gezeigt $]$ Hans has Maria, Dat. a picture shown and Paul has Anna, Dat. a picture shown 'Hans showed Maria, and Paul Anna, a picture.'

Despite the fact that unfocused indefinites which are not anchored in the context cannot serve as antecedents for pronouns, the subjects they denote may be topicalized by a definite expression. As to our ellipsis construction (48), it presupposes that the two subjects form a set which can be topicalized by a definite expression like both pictures in a sentence such as Maria and Anna liked both pictures.

Now let's compare (46.iv), where only a distributive reading is possible, with $(26=49)$, in which the indefinite is unfocused and contained in a shared constituent but appears together with a focused constituent.

(49) A: [F Wann] hat Paul Anna und hat Hans Frieda ein Bild gezeigt?

When has Paul to Anna and has Hans to Frieda a picture shown

'When did Paul show Anna, and Hans Frieda, a picture?'

B: Paul hat Anna und Hans hat Frieda [F am SONNTAG] ein Bild gezeigt.

Paul has to Anna and Hans has to Frieda on Sunday a picture shown

'Paul showed Anna, and Hans Frieda, a picture on Sunday."

Here the indefinite can get either a unique or a distributive reading. The difference between (46.iv) and (49) is that with the former we have two propositions, each being the alternative to the other and each presupposing a non-contextually anchored subject, whereas constructions like (49) do not have this presupposition. The construction (49) presupposes either that Paul showed one picture to Anna and Hans showed a different picture to Frieda or that Paul showed Anna the same picture that Hans showed Frieda. Unlike constructions such as (48), which can be syntactically represented as ellipses, structures like (49) cannot be represented as an ellipsis. The reason, as the reader may remember, lies in the focus interpretation theory, which states that the shared constituent must be beyond the actual coordination - cf. section Two - and that an ellipsis representation would not deliver the unique reading of the indefinite expression - cf. 3.2. 


\section{Conclusion}

To summarize the results of this paper, we may state the following. As with noncoordinate structures, the semantics of indefinites appearing in shared constituents is underdetermined with regard to the specific or non specific reading of these indefinites; and, not unlike indefinites which are found in the connex with a distributing operator, it is not specified whether these indefinites may have a unique or a distributive reading. The possible readings are influenced by the information structural status of the respective indefinite. Thus we note that possible readings may be limited by defocusation or by the background status of the indefinite.

The greatest number of readings is obtained where the indefinite is in a focused shared constituent, as in (22). According to the focus interpretation theory, such focused shared constituents must lie beyond the actual coordination. Appearing in a focused shared constituent which represents presentational focus, the indefinite may have (i) a specific unique reading, (ii) an non specific unique reading, and (iii) an non specific, distributive reading. To obtain the third reading, it has proven useful to form pairs of sets out of sets of pairs. This set formation also accounts for the possible use of plural pronouns which refer to these sets, and for the plural number agreement of a verb with the set of subjects in cases where the verb is in a focused shared constituent. Departing from the idea that an indefinite denotes a subject that may or may not be anchored in the context and that the context anchoring makes the denoted entity specific, we conclude that the indefinite gets a specific reading if the subject it denotes is anchored. The indefinite is then accessible for pronouns. This is what is called the specific unique reading. On the other hand, an unanchored subject remains non specific and cannot be coreferent with a pronoun. Here we speak of the non specific unique reading. To get a distributive reading, a covert distributing operator must be attached to the pair of sets. Because such an operator blocks the context anchoring of the denoted subjects, indefinites in the operator's scope are said to have an non specific, distributive reading. Indefinites in focused shared constituents are not limited with regard to their possible readings precisely because they are in focus. In this case there is nothing presupposed that could exclude any of the three readings.

If an indefinite is unfocused in a shared constituent containing a focused constituent, as in (26), it is presupposed that the subject it denotes has been denoted previously and that the subject has not been anchored. What is not presupposed is whether or not the indefinite lies in the scope of a distributive operator. Thus constructions like (26) presuppose either the non specific unique reading or the distributive reading of the indefinite and exclude the specific unique reading. They may therefore have the non specific unique reading and the non specific, distributive reading.

If an indefinite is in an unfocused shared constituent, as in (48), it is presupposed that the subject it denotes has not been anchored and that the indefinite has been in the scope of a distributive operator. Unlike constructions such as (22) and (26), constructions like (48) may be represented syntactically as ellipses as this does not violate the information structural symmetry following from the focus interpretation theory. 
In concluding this report, let me again point out the open questions associated with the theory outlined thus far. It remains to be demonstrated how the formation of a pair of sets is derived from a set of pairs and how the pair-of-set-interpretation can be kept transparent vis-à-vis the set-of-pair-interpretation. Further, a more thorough examination of Wilder's (1998) theory on constructions with shared constituents - cf. (35) would be worthwhile in order to assess whether it can be also applied to constructions where the shared constituent is not focused and which we have represented here as ellipses. This would be beneficial as it would allow for one single syntactic representation of structures with shared constituents instead of two. Because such a syntactic representation would be more likely to preclude sloppy readings-which are, by the way, not a serious problem for elliptical constructions, cf. (28), (31), and (33)-the idea of set formation and distribution may offer a promising avenue for accessing this problem.

\section{References}

Büring, D; Hartmann, K. (1998): Asymmetrische Koordination. Linguistische Berichte 174. 172-201

Chierchia, G. (1992): Anaphora and Dynamic Logic. Linguistics and Philosophy 15. 111-183

Dekker, P. (1997): On denoting Descriptions. Unp. ms.

Dekker, P. (1999): Speaker's Reference, Descriptions and Information Structure. To appear in: Journal of Semantics

Diesing, M. (1992): Indefinites. Cambridge, Ma.

Eckardt, R. (1996): Intonation and Predication. Arbeitspapiere des Sonderforschungsbereichs 340: Sprachtheoretische Grundlagen für die Computerlinguistik. No. 77, University of Tübingen.

Fodor, J. \& Sag, I. (1982): Referential and Quantificational Indefinites. Linguistics and Philosophy 5. 355-398

Grootveld, M. (1994): Parsing Coordination Generatively. Leiden

Heim, I. (1983): File change semantics and the familiarity theory of definiteness. In: Bäuerle, R.; Schwarze, Ch.; von Stechow, A. (eds.): Meaning, Use, and Interpretation of Language. Berlin; New York.

von Heusinger, K. (1997): Salienz und Referenz, Der Epsilonoperator in der Semantik der Nominalphrase und anaphorischer Pronomen. Berlin

Hilbert, D.; Bernays, P. (1968\{1934]): Grundlagen der Mathematik. Vol. II, 2. ed. Berlin; Heidelberg; New York

Krifka, M. (1998): Non-novel Indefinites in Adverbial Quantification. Unp. ms.

Lang, E. (1984): The Semantics of Coordination. Amsterdam

Lasersohn, P. (1995): Plural, Conjunction and Events. Dordrecht; Boston; London

Reinhart, T. (1995a): Quantifier scope. To appear in: Reinhart, T. (ed.): Interface Strategies. Cambridge, Ma:

Reinhart, T. (1995b): Interface Strategies. OTS Working Papers OTS-WP-TL-95-002

Reinhart, T. (1997): Quantifier Scope: How Labor is Divided between QR and Choice Functions. Linguistics and Philosophy 20,4. 335-397

Rooth, M. (1992): Ellipsis Redundancy and Reduction Redundancy. In: Berman, S.; Jestvol. A. (cds.): Proceedings of the Stuttgart Ellipsis Workshop 1992 (= Arbeitspapiere des Sonderforschungsbereichs 340: Sprachtheoretische Grundlagen für die Computerlinguistik. No. 29). University of Tübingen

Tancredi, Ch. (1992): Deletion, Deaccenting and Prcsupposition, MIT Working Papers in Linguistics

te Velde, J.R. (1996): Coordination and Antisymmetry Theory: Some Evidence from Germanic. American Journal of Germanic Linguistics \& Literatures 8,2. 135-175

Wilder, Ch. (1994): Coordination, ATB and Ellipsis. GAGL 37. 291-331

Wilder, Ch. (1995): Rightward Movement as Leftward Deletion. Unp. ms. 
Wilder, Ch. (1996): V2-Effekte: Wortstellung und Ellipsen. In: Lang, Ewald; Zifonun, Gisela (eds.): Deutsch-typologisch. Berlin; New York. 142-180

Wilder, Ch. (1998): Shared constituents and linearization. Paper held at the "Workshop on Ellipsis in Conjunction". ZAS Berlin, Oct. $2-3,1998$

Williams, E. (1978): Across-The-Board Rule Application. Linguistic Inquiry 9. 31-43

Winkler, S. (1997): Ellipsis and Information Structure in English and German: The Phonological Reduction Hypothesis. Arbeitspapiere des Sonderforschungsbereichs 340: Sprachtheoretische Grundlagen für die Computerlinguistik. No. 51. University of Tübingen

Winter, Y. (1996): Choice Functions and the Scopal Semantics of Indefinites. OTS Working Papers OTSWP-TL-96-004

Winter, Y. (1997): Choice Functions and the Scopal Semantics of Indefinites. Linguistics and Philosophy 20,4. 399-467

Kerstin Schwabe

Zentrum für allgemeine Sprachwissenschaft, Typologie und Universalienforschung

Jägerstr. 10-11

10117 Berlin

Germany

schwabe@zas.gwz-berlin.de 


\section{Morphological Complexity and Conceptualization: The Human Body}

The arbitrariness of the linguistic sign (,l'arbitraire du signe“) and especially of the word is one of the fundamental assumptions in Saussure's Cours de Linguistique Générale:

Le lien unissant le signifiant au signifié est abitraire, ou encore, puisque nous entendons par signe le total résultant de l'association d'un signifiant à une signifié, nous pouvons dire plus simplement: le signe linguistique est arbitraire [...]; nous voulons dire qu'il est immotivé, c'est-à-dire arbitraire par rapport au signifié, avec lequel il n'a aucune attache naturelle dans la réalité. (Saussure 1915: 100-01)'

In the one hundred years since the publication of the Cours, linguistic investigation has modified this assumption, showing that some features of linguistic structure in phonology, morphology and syntax are motivated. In this context, scholars of Natural Theory have contributed important results, such as Stampe, Mayerthaler, Wurzel, Dressler, Haiman and many others. By contrast, the lexicon is still considered unpredictable and arbitrary:

The fact that English ear means what it does and functions as a noun does not follow from any general property of the language [...] This fact is completely 'exceptional' in the sense that there is nothing else about the language from which it could have been predicted. Such arbitrariness is typical of the lexicon, which is to this extent the repository of what is idiosyncratic and unpredictable about linguistic forms.

(Anderson 1985: 3-4)

Anderson's remark on the arbitrariness of the lexicon is true in the sense that a lexical unit does not result from any other structural property of a given language. However the motivation for certain lexical structures is to be found not in internal, but in external motivations, more precisely, in cognitive factors underlying which motivates the linguistic expression. The supposed arbitrariness of lexical items may be one of the reasons why the relationship between lexical semantics and morphology is little investigated. As Levin and Hovav (1998) note:

The relation between lexical semantics and morphology has not been the subject of much study. This may be surprising, since a morpheme is often viewed as a minimal Saussurian sign relating form and meaning: it is a concept with a phonologically composed name. [...] Since morphology is the study of the structure and derivation of complex signs, attention could be focused on the semantic side (the composition of complex concepts) and the structural side (the composition of the complex names for the concepts) and the relation betwcen them.

(Levin/Hovav 1998: 248)

In this squib, I want to argue that the morphological structure of words is, at least to some extent, motivated. As an example I have choosen the partonomic (and for the less

\footnotetext{
1 Emphasis in the original text.
} 
part taxonomic) nomenclature ${ }^{2}$ of the human body. While important work by Brown et alii (1973), Anderson (1978) and Schladt (1997) exists on this topic, these analyses focus on the conceptualization of body-parts and their semantics, but not on their morphological representation. ${ }^{3}$

In the following, I want to check two predictions about the morphological complexity of lexical items denoting parts of the human body. The first assumption is that the most canonical body-parts ${ }^{4}$ are always expressed by mono-lexematic items. The second one consists in the assumption that body-parts of the lowest levels in the hierarchy are always morphologically complex. ${ }^{5} \mathrm{~A}$ set of six body-parts has been analysed in 27 languages. The set consists of two canonical (HEAD and EAR) and of one from the lowest level of the hierarchy (TOENAIL). For this I have adopted a sample from Schladt (1997) and a small one compiled by myself. ${ }^{6}$ In table 1 are listed the results for 18 languages spoken in Kenya (Cushitic, Nilotic and Bantu):

table 1

\begin{tabular}{|l|c|c|}
\hline concept & mono-lexematic & complex construction \\
\hline HEAD & 18 & 0 \\
\hline EAR & 18 & 0 \\
\hline SPINAL COLUMN & 8 & 10 \\
\hline THUMB & 3 & 15 \\
\hline NJPPLE & 1 & 17 \\
\hline TOENAIL & 0 & 18 \\
\hline
\end{tabular}

In table 2 are listed the results of a sample of other nine languages (German, KhalkhaMongolian, Upper Sorbian, Bahasa Indonesian, Hungarian, Turkish, Vietnamese, Finnish and English):

table 2

\begin{tabular}{|l|c|c|}
\hline concept & mono-lexematic & complex construction \\
\hline HEAD & 9 & 0 \\
\hline EAR & 9 & 0 \\
\hline THUMB & 5 & 4 \\
\hline NIPPLE & 4 & 5 \\
\hline SPINAL COLUMN & 2 & 7 \\
\hline TOENAIL & 0 & 9 \\
\hline
\end{tabular}

2 Partonomy refers to the relationship , $\mathrm{x}$ is part of $\mathrm{y}^{\prime}$ and , $\mathrm{y}$ is part of z' (e.g. Tisch, Tischbein, Tischbeinende). In contrast to taxonomy, in partonomic relations, switching beween the different levels of the hierarchy is not possible. For example, you can say a toenail is part of the toe, but not the toenail is part of the leg. Body-part partonomies contain normally five levels (Brown et al. 1973).

3 Matisoff (1978) includes phonological aspects.

4 I adapt 'canonical' from Schladt (1997: 69-74) who prefers this term to 'prototypical' speaking of body-parts.

5 A third assumption, not emprically examined in this squib, is the prediction that the majority of the terms for the lower half of the body are morphologically more complex compared to those of the upper half. This results from the conceptual hierarchy UP $\rightarrow$ DOWN: "oben ist unmarkiert - unten ist markiert" (Schladt 1997: 81).

6 The criteria for a representative sample of languages for the typology of lexical semantics need not follow the same principles as for grammatical typology, i.e. geographical distribution, genetic relationship and grammatical structure (see Koch/Steinkrüger in press). 
The results show that the expressions for HEAD and EAR are always mono-lexematic, whereas the expression for TOENAIL is always morphologically complex. The non- or less canonical body-parts in the middle sphere show a mixed behaviour. This result exactly shows a correspondence between conceptual markedness and morphological complexity.

With some examples taken from the nomenclature of the human body, I have demonstrated that the morphological complexity of the lexicon is not totally arbitrary. I suggest, this has an external, i.e. non-linguistic, motivation, more precisely from human cognition. Further investigation may go into more detail.

\section{References}

Anderson, Elaine S. (1978): Lexical Universals of Body-Part Terminology, In: Greenberg, Joseph H. et al. (eds.): Universals of Human Language. Volume 3: Word Structure. Stanford/Ca.: Stanford University Press. 335-368

Anderson, Stephen R. (1985): Typological distinctions in word formation. In: Shopen, Timothy (ed.): Language Typology and syntactic description. Volume III: Grammatical Categories and the Lexicon. Cambridge; etc.: Cambridge University Press. 3-56

Brown, B.; Breedlove, D.; Raven, P. (1973): General principles of classification and nomenclature in folk biology. American Anthropologist 75. 214-242

Koch, Peter; Steinkrüger, Patrick O. (in press): Poligenesi lessicale e dati ,empirici'. To appear in: Atti del XXXIII Congresso Internazionale della Società Linguistica Italiana (Napoli 1999)

Levin, Beth; Rappaport Hovav, Malka (1998): Morphology and Lexical Semantics. In: Spencer, Andrew; Zwicky, Arnold M. (eds.): The Handbook of Morphology. Oxford: Blackwell. 248-271

Matisoff, James A. (1978): Variational semantics in Tibeto-Burman: the 'organic' approach to linguistic comparison. Philadelphia: Institute for the Study of Human Issues

Saussure, Ferdinand (1915): Cours de Linguistique Générale. Edition by Tullio de Mauro. Paris: Payot, 1984

Schladt, Mathias (1997): Kognitive Strukturen von Körperteilvokabularien in kenianischen Sprachen, Köln: Universität, Institut für Afrikanistik

Patrick Oliver Steinkrüger

Zentrum für allgemeine Sprachwissenschaft,

Typologie und Universalienforschung

Jägerstr. 10-11

10117 Berlin

Germany

steinkrueger@zas.gwz-berlin.de 